\title{
Desarrollo humano y condiciones de vida en Canadá
}

DOI: $10.32870 /$ mycp.v6i19.200

Ramón Robledo Padilla*

$\mathrm{E}$ n esta contribución me propongo destacar que Canadá es un país que ocupa los primeros lugares en el Informe de desarrollo humano que presenta el programa de las Naciones Unidas. Asimismo, señalar que existe cierta relación entre países desarrollados y primeros lugares en el Índice de Desarrollo Humano (IDH). Finalmente, decir que a pesar de los primeros lugares que ocupan los países desarrollados en la clasificación del índice, son éstos, mediante sus políticas y niveles de crecimiento elevados, los que han contribuido en mayor grado a un incremento en el deterioro de las condiciones de vida del planeta.

Cada año, desde 1990, el Programa de las Naciones Unidas para el Desarrollo encarga a un grupo de expertos independientes la elaboración del Informe de desarrollo humano. Aunque en el informe se analiza el ingreso per cápita como una forma de medir el bienestar de la población, este indicador no es suficiente para dar cuenta del desarrollo humano. El escepticismo a la relación que establecía que un incremento en los ingresos nacionales daba como resultado un mayor bienestar en el país es cada vez mayor desde la década de los ochenta. La deshumanización, la contaminación, la inseguridad, la desigualdad entre los sexos, son aspectos que no se contabilizan positiva o negativamente dentro de la sociedad. De esta manera, los datos que presenta el informe se relacionan con otros facto-

* Investigador del Departamento de Estudios del Pacífico de la Universidad de Guadalajara. res constituyendo una base más amplia, como son la esperanza de vida y la alfabetización.

El desarrollo humano es un concepto amplio que se define como el proceso mediante el cual las oportunidades de los individuos se amplían para tener una vida más segura, sana y digna; se toman en cuenta aspectos diversos como la igualdad de oportunidades para la mujer con respecto al hombre, libertad de expresión, disfrutar de un medio ambiente limpio, entre otros. Con estos indicadores, algunos países que tengan ingresos per cápita más altos que otros pueden estar ubicados en el índice de desarrollo humano por debajo de aquellos que tengan ingresos per cápita menores. Es el caso del informe de 1999, en el cual se presenta el ingreso per cápita en dólares internacionales, ${ }^{1}$ donde Singapur, con un nivel de 28460 dólares en 1997, ocupaba el lugar número 22 en el índice de desarrollo humano; en cambio Canadá, con 22480 dólares, ocupó la primera posición.

A pesar de que el informe ha tenido una extensa difusión, también ha sido objeto de muchas críticas tanto en sus aspectos metodológicos como en las fuentes de información utilizadas.

En relación con la metodología que se emplea para calcular el índice de desarrollo humano, ${ }^{2}$ son cuatro las críticas más importantes: ${ }^{3}$ en primer lugar, se cuestiona la utilización de ponderadores iguales. Se plantea que no hay razón para asignar $1 / 3$ a cada una 
de las tres variables que se utilizan para construir el índice; esto, según algunos autores, es igual a sumar naranjas con pepinos y guayabas. Para algunos investigadores, el ingreso debería tener una mayor ponderación, puesto que puede ser utilizado para adquirir salud y educación; otros plantean que el ingreso debería tener una ponderación menor, puesto que es sólo un medio para lograr el desarrollo humano y no un fin en sí mismo, como los otros dos indicadores.

Otra de las críticas se refiere a los distintos recorridos de las variables. Se señala que el índice es sensible a la elección de valores extremos para cada dimensión, este hecho es importante porque se afectan las posiciones relativas de los países en el ordenamiento según el índice. Ejemplo, si existen dos indicadores de privación, I y II, que tienen valores entre 0 y 100 . Si el país A tiene 50 y 75 en cada indicador, y el país B tiene 75 y 50 respectivamente, el índice para ambos países es 0.625 . Si se aumenta el valor máximo de la privación II a 200, el país A tendría un IDH de 0.438 , y el país B lo tendría igual a 0.5 , con lo cual mejoraría su posición en el ranking respecto al otro país.

La tercera crítica señala que la utilización de valores extremos variables no permite hacer comparaciones del IDH ínter temporalmente, ya que los valores extremos utilizados para cada año son distintos. Esto implica que un país que mejore su condición de privación en una proporción menor al crecimiento del valor máximo podría, incluso, ver reducido su IDH.

Finalmente, el último de los cuestionamientos más importantes desde el punto de vista metodológico, es el fijar un umbral a partir del cual no se toman en cuenta los ingresos adicionales; esto se contrapone con el hecho comúnmente aceptado de que, con un mayor ingreso se incrementan las posibilidades de elección de las personas, asimismo, se daría una mayor ponderación relativa a los otros dos indicadores.
En cuanto a la información que se utiliza para elaborar el IDH, el principal cuestionamiento es que, al no existir una amplia disponibilidad de datos, es común que se utilicen proyecciones y estimaciones que en muchas ocasiones están muy alejadas de la realidad.

En el informe de 2000, por séptimo año consecutivo, Canadá ocupó el primer lugar en la clasificación del IDH (México, el lugar 55). De acuerdo con el informe, que comprende 174 países, Canadá cuenta con las mejores condiciones y oportunidades para que el ser humano pueda vivir de la mejor manera. Esto no quiere decir que sea el lugar óptimo, pero sí el mejor lugar de todos los países analizados. No obstante que Canadá logró mejorar el valor de su índice en los siguientes dos años al pasar de .935 en el año 2000 a .936 en 2001 y .940 en 2002, su posición bajó del primero al tercer lugar. En esos años el primer lugar lo ocupó Noruega, que logró un incremento en el valor de su índice de .934 en el año 2000 a .939 y .942 en los dos años siguientes.

Con el paso de los años, los informes cada vez son más amplios debido al hecho de que incorporan nuevas variables de medición. En el informe de 1995 se introdujo un nuevo índice para ver las diferencias de desarrollo humano entre hombres y mujeres; asimismo, en el reporte de 1997 se introdujo un nuevo concepto para medir la pobreza tanto en los países desarrollados como subdesarrollados. ${ }^{4}$

En el índice de desarrollo relacionado con la mujer (en el cual se analizan los mismos indicadores del índice de desarrollo humano), en 1999 Canadá ocupó el primer lugar. En cuanto al poder de decisión que tienen las mujeres en cada país, donde se cuenta la proporción de mujeres que ocupan puestos directivos, de administración y en el poder legislativo, Canadá apareció en la cuarta posición.

En términos de expresión material, de acuerdo con cifras del Banco Mundial, en 1997 Canadá se ubicó en el lugar nueve en cuanto a la generación del producto interno bruto, con 
583000 millones de dólares. Si se toman los datos del ingreso per cápita en dólares internacionales, el rango que ocupa Canadá es congruente con las anteriores cifras, al situarse en el lugar diez con 21860 dólares.

De esta manera, se pueden analizar otros países donde se da una relación en forma general (aunque no en todos los casos, México es un ejemplo de eso) entre lo que es el tamaño de la economía y su ubicación en los primeros lugares de la clasificación de desarrollo humano. La razón de que Canadá esté clasificada en el primer lugar en cuanto a desarrollo humano, y en el lugar diez en cuanto a ingreso per cápita en dólares internacionales, se debe a que, como se mencionó anteriormente, el índice de desarrollo humano toma en cuenta otros factores que no se expresan de manera material. De cualquier forma, podemos observar que existe por lo general una relación entre lo que se conoce como economías desarrolladas y su clasificación en los primeros lugares en desarrollo humano.

Una encuesta realizada por un grupo de profesionales, en 1997, confirma de alguna manera que Canadá se encuentra catalogado como uno de los mejores lugares para vivir. En esta encuesta, que estuvo bajo la supervisión del grupo Angus Reid, se entrevistaron a 5700 adultos de 20 países (incluyendo a Canadá) y se realizó en 24 idiomas diferentes. A los participantes se les pidió que mencionaran los países en los que desearían vivir después del propio; en su mayoría, de los 20 países encuestados, colocaron a Canadá en el primer lugar. Los entrevistados consideraron que Canadá cuenta con los aspectos necesarios para disfrutar de una mejor calidad de vida como son la salud, medio ambiente limpio y tranquilidad. ${ }^{5}$

Otro de los aspectos que fortalece el que Canadá sea considerado un lugar bueno para vivir son sin duda los reconocimientos que se hicieron en el ámbito internacional. Tal es el caso cuando la comisión mundial de la UNESCO reconoció, y puso como ejemplo para otros países, la forma en que Canadá ha abordado el multiculturalismo. En 1971 Canadá fue el pri- mer país en el mundo en adoptar una política multicultural. En 1986 el gobierno aprobó la ley de equidad en el empleo y en 1988 la del multiculturalismo canadiense. Por medio de esta política multicultural, el gobierno canadiense pretende construir una sociedad más incluyente basada en el respeto, la equidad y en la completa participación de todos los ciudadanos, sin hacer distinción de raza, origen étnico, lengua o religión. ${ }^{6}$

Además de lo anterior, en un contexto en el que cada día existe mayor inquietud por los aspectos del medio ambiente entre investigadores, autoridades gubernamentales y organizaciones no gubernamentales, Canadá es un protagonista en el plano internacional. En la búsqueda por hacer un uso más racional de los recursos naturales y tener un mejor control sobre las prácticas que provocan daños al medio ambiente, el 11 de junio de 1971, Canadá fue el segundo país (después de Francia) que estableció un ministerio formal del medio ambiente. $^{7}$

Esta serie de elementos, que contribuyen de manera importante hacia una mejor calidad de vida y que no son fáciles de medir en términos materiales, aunada a los bienes materiales, que reflejan las capacidades productivas del país, son lo que dan como resultado la clasificación de los países en el índice de desarrollo humano.

Resulta paradójico que los informes de desarrollo humano, por un lado, clasifican los países desarrollados en los primeros lugares en cuanto a mejores oportunidades para los individuos y, por consiguiente, un mejor desarrollo humano, y por el otro, se menciona que son éstos quienes deben realizar mayores esfuerzos para revertir el proceso de empobrecimiento y deterioro de las condiciones sociales de la mayoría de la población que habita nuestro planeta, no sólo en el plano internacional sino en cada país.

Por ejemplo, en el Informe de desarrollo humano de 1998 se destaca el problema de los elevados niveles de consumo en los países de- 
sarrollados y de la forma en que éste perjudica a los más pobres. El informe señala que 20\% de las personas de los países de mayor ingreso realizaron un gasto del consumo privado de $86 \%$, en cambio, $20 \%$ de los habitantes de los países más pobres, realizaron un consumo privado de $1.3 \%$. En la misma proporción, poseen $87 \%$ de la flota mundial de vehículos, y el $20 \%$ más pobre posee menos del $1 \%$. El consumo, que está creciendo de manera vertiginosa, pone en peligro el medio de vida al aumentar la degradación y el agotamiento de los recursos naturales por la emisión de tóxicos que contaminan el medio ambiente.

En el reporte de 2000, 20\% de los más ricos en Canadá concentraron $39.3 \%$ del ingreso total y $20 \%$ más pobre concentró $7.5 \%$. En el caso de México la relación fue 58.2 y 3.6, respectivamente. Esto quiere decir que a pesar del desarrollo alcanzado, la brecha entre pobres y ricos no sólo es un problema entre países sino incluso dentro de cada país. El caso más claro se presenta en Estados Unidos. En el informe de 2000, por un lado, Estados Unidos ocupa el tercer lugar en cuanto a desarrollo humano y, por otro, tomando en consideración sólo a los países desarrollados, es el país donde hay más pobres.

Asimismo, se señala que en los países industrializados, la generación per cápita de desechos casi se ha triplicado en los últimos 20 años. Las emisiones de dióxido de carbono se cuadruplicaron en los últimos 50 años. Esto ha ocasionado un sobrecalentamiento de la Tierra que amenaza con aumentar la frecuencia de las tormentas y las sequías, acelerar la extinción de algunas especies, difundir enfermedades contagiosas y posiblemente provocar cambios que alteren la fuerza del clima mundial. Según el informe, un niño nacido en el mundo industrializado agrega más consumo y contaminación a lo largo de su vida que entre 30 y 50 niños nacidos en países en desarrollo.

Así, 20\% de las personas que viven en los países desarrollados realizan $53 \%$ de las emisiones de dióxido de carbono, y la quinta parte más pobre emite $3 \%$. México, China, Brasil e
Indonesia se encuentran entre los países en desarrollo que más emisiones realizan. Pero si se les compara en términos per cápita con los países desarrollados, la relación es baja. Por ejemplo, en México la emisión per cápita es de 3.9 toneladas métricas por año, comparado con 20.5 toneladas métricas en Estados Unidos y 10.2 en Alemania. El recalentamiento de la Tierra provocado por estas pautas de consumo será devastador principalmente en los países pobres. Los pobres están más expuestos a estos peligros y tienen menor capacidad para protegerse.

Aunque existe una preocupación por el consumo creciente, no es clara la existencia de un mayor grado de conciencia entre la población ni formas precisas para revertir este proceso. El informe señala que la definición de lo que constituye una necesidad está cambiando, y las distinciones entre lujo y necesidad se están desvaneciendo. Por ejemplo, en el decenio de 1980, Brasil, China, Malasia, México y Sudáfrica poseían dos a tres veces la cantidad de automóviles que tenían Alemania, Austria y Francia cuando estos últimos tenían un nivel de ingreso similar a los primeros, hace treinta años. Es posible que la pobreza se profundice a medida que las familias compitan por satisfacer niveles de consumo en aumento, limitando el gasto en los alimentos, la educación y la salud hasta eliminarlos. Este cambio en los valores impulsa probablemente a que la gente gaste más horas trabajando, y deje menos tiempo para la familia, los amigos o la comunidad.

Para concluir podemos decir que la relación entre el crecimiento económico y el progreso humano no es automática. El crecimiento debe estar acompañado por una mejor distribución de los recursos. El cambio de actitud, sin duda, es un reto importante; se requiere voluntad política para poner en el centro de la discusión el desarrollo del ser humano y no privilegiar el mayor enriquecimiento de unos cuantos. John Kenneth Galbraith escribió hace 42 años acerca de la opulencia privada en medio de la miseria pública. Lejos de reducirse, 
los contrastes han aumentado, y a ellos se agregan la miseria privada y ambiental.

Es lamentable no realizar esfuerzos para evitar el crecimiento económico sin empleo, sin equidad, sin participación de la mayoría de la población que queda excluida de este tipo de decisiones. Cada vez existe más consenso en señalar (incluyendo el informe de 1997) que al ritmo actual de progreso, los países de desarrollo humano bajo se tardarán un siglo o más para alcanzar a los países de desarrollo humano alto.

Como lo señaló Amartya K. Sen, ¿por qué se tiene que aceptar que los derechos de propiedad han de ser una consideración prioritaria a otras consideraciones como las del sufrimiento o la muerte de millones de personas?

\section{Notas}

1 Es una medida más precisa para hacer comparaciones internacionales, ya que toma en cuenta la diferencia de precios en cada país.

2 Para construir el índice de desarrollo humano se toman en cuenta tres indicadores: la esperanza de vida, el nivel de escolaridad y el producto interno bruto per cápita; asimismo, está basado en un enfoque de "reducción de brechas", es decir, el desarrollo se mide a partir de la reducción entre la variable y su máximo valor posible, por ejemplo, si se asume una esperanza de vida máxima de 80 años, un aumento en la esperanza de vida de 60 a 70 años, representa una mejora de 50 por ciento (la brecha se reduce de 20 a 10 años).

3 Xavier Mancero. La medición del desarrollo humano: elementos de un debate. Naciones Unidas. CEPAL. ECLAC. Serie: estudios estadísticos y prospectivos núm. 11. División de Estadísticas y Proyecciones Económicas. Santiago de Chile, marzo de 2001.

4 Para medir el grado de pobreza, en los países subdesarrollados se contabilizan datos como: porcentaje de población estimada que no sobrevivirá hasta los 40 años, niños menores de cinco años con peso insuficiente, niveles de ingreso entre $20 \%$ más rico y $20 \%$ más pobre, y porcentaje de alfabetización, de personas sin acceso a servicios de salud, agua potable y saneamiento. Para medir la pobreza en los países desarrollados se toma en cuenta: el número de personas que se estima no sobrevivirá hasta los sesenta años, el grado de concentración del ingreso entre $20 \%$ más rico y el más pobre, y el porcentaje de analfabetos y desempleados.

5 Wysiwyg://110/http://www.cio-bic.gc.ca/facts/ mondocan_e.html 28/07/2000.

6 Wysiwyg://119/http://www.cio-bic.gc.ca/facts/multi_e. html.

7 Wysiwyg://140/http://www.cio-bic.gc.ca/facts/env_e.htm.

\section{Bibliografía}

http://www.undp.org (Informes sobre Desarrollo Humano de las Naciones Unidas, 1990-2000). 